\title{
LÍQUIDO CEFALORRAQUEANO EM 50 PACIENTES COM AIDS
}

\author{
S.L.HINRICHSEN", LATAIDE JR.**, F. TRAVASSOS $* * *$ P.TRAVASSOS***,

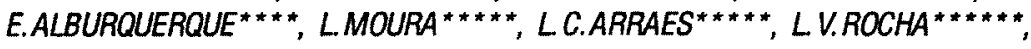 \\ M.R.G.AMORIM***** , LM.D.R.LUZ"*****, A. BRAGA*****
}

RESUMO - Foram estudados 50 pacientes com AIDS. Todos estes pacientes apresentavam anticorpos antiHIV1 (ELISA) e preenchiam os critérios de pontuaçåo OPAS/Caracas de definição de casos de AIDS em adultos. A análise do liquido cefalorraqueano (LCR) incluiu: pressão; citologia (número de células e aspectos citomorfológicos); proteina total e eletroforese; concentraçðes de glicose, cloretos e testes imunológicos para sifilis, toxoplasmose e infecçðes virais (citomegalovirus, varicela-zoster, Herpes simplex, e HIV1). Investigaçðes bacteriológicas e micológicas (pesquisa direta e cultura), além de teste de aglutinação (látex) para Cryptococcus foram também realizados. Os testes imunológicos usados foram fixação do complemento, imunofluorescência indireta, hemaglutinação passiva e/ou ELISA. Todos os LCR foram analisados no mesmo laboratório seguindo sempre a mesma metodologia. O LCR esteve alterado em 45 pacientes $(90,0 \%)$ dos 50 pacientes estudados. As principais alteraçðes encontradas no LCR foram: aumento de gamaglobulina em 25 casos $(55,5 \%)$; aumento da proteína total em $23(51,1 \%)$; hipercitose em $22(48,9 \%)$ e diminuição dos cloretos em $18(40,0 \%)$. A deteç̧ão de anticorpos anti- HIVI estiveram presentes em 42 pacientes $(93,3 \%)$. Toxoplasmose isolada ou associada a outros agentes foi a infeç̧ăo oportunista mais frequente, detectada em 26 casos $(57,7 \%)$. O LCR deverá ser sempre analisado em todos os pacientes com AIDS, com ou sem sintomas neurológicos.

PALAVRAS-CHAVE: AIDS (SIDA), líquido cefalorraqueano, infeç̧ðes oportunisticas.

\section{Cerebrospinal fluid in 50 AIDS patients}

ABSTRACT - Fifty AIDS patients were studied. All patients had anti-HIV antibodies (ELISA) present and met OPAS/ Caracas punctuation criteria for AIDS cases in adults. Cerebrospinal fluid (CSF) analysis included pressure, cytology (number and cytomorphological aspects), total protein and electrophoresis, glucose and chloride concentration. Bacteriological and mycological investigations were performed as well as agglutination tests for Cryptococcus. Complement fixation, indirect immunoflorescence, passive hemagglutination and/or ELISA tests were performed for syphilis, toxoplasmosis, viral and fungal infections. All CSF analysis were made in the same laboratory following the same methodology. CSF was aiterated in 45 cases (90.0\%) of the 50 patients studied. The most important alterations observed were: gammaglobulin (55.5\%) and total protein (51.1\%) increase, hypercytosis (48.9\%) and decrease of chloride concentration (40.0\%). HIV antibodies were detected in 42 patients $(93.3 \%)$. Toxomoplamosis, isolated or associated to other agents, was the most frequent opportunistic infection $(57.7 \%)$. Cerebrospinal fluid should always be examined in AIDS patients with or without neurological symptoms.

KEY-WORDS: AIDS, cerebrospinal fluid, opportunistic infections.

A possibilidade de replicação, em tecido cerebral, do vírus da imunodeficiência humana (HIV), bem como o encontro de receptores de membrana em células nervosas, semelhantes aos de linfócitos

Serviço de Doenças Infecciosas e Parasitárias (DIP) do Hospital das Clínicas (HC)/Núcleo de Ensino, Pesquisa e Assistencia em AIDS (NEPA), Universidade Federal de Pernambuco (UFPE): *Chefe do Serviço de DIP, Coordenadora do NEPA; **Professor Adjunto do Departamento de Neuropsiquiatria; ***aboratório de Neurodiagnóstico do HC/UFPE; ****Serviço de Imagens do Hospital Albert Sabin; *****Professor Auxiliar do Serviço de DIP e NEPA/UFPE; ******Doutoranda do HC e Estagiária do NEPA/UFPE. Aceite: 1-fevereiro-1996. 
$T$, permitem concluir que há tropismo viral, nāo só para as células T4, como também por células do sistema nervoso central (SNC). O HIV é, portanto, um vírus neurotrópico e a invasão do SNC ocorre precocemente no curso da infecção, no mesmo tempo da soroconversão'. O comprometimento do SNC nos pacientes com AIDS pode ocorrer em qualquer fase da doença ${ }^{4}$. O líquido cefalorraqueano (LCR) tem-se mostrado material propício, tanto para o reconhecimento da presença do HIV no SNC como para o estabelecimento de infeç̧⿸尸es secundárias ${ }^{3-5,8,9}$, podendo ser diagnóstico para várias infeç̧ões comumente observados na AIDS.

O presente estudo tem o objetivo analisar os achados do LCR em 50 pacientes com AIDS, independentemente de apresentarem ou não sinais e/ou sintomas neurológicos.

\section{CASUÍSTICA E MÉTODOS}

Foram estudados 50 pacientes portadores do HIV, confirmados laboratorialmente por análises sorológicas de anticorpos anti-HIV (ELISA ou Western Blot), admitidos na enfermaria de DIP do HC-UFPE no periodo de abril-1991 a agosto-1993.

Em relação à fase clínica da AIDS, todos os 50 pacientes (100\%) pertenciam ao grupo IV (subgrupo B, $C, \mathrm{De}$ E) da classificação do Centers for Disease Control (CDC) e preenchiam o critério diagnóstico de pontuação OPAS/Caracas. Do total de pacientes examinados $45(90,0 \%)$ eram do sexo masculino e cinco $(10,0 \%)$ do feminino, o que representou uma razão de 9:1, aproximadamente. A idade dos pacientes à admissão hospitalar variou de 21 a 53 anos, com média de 31,92 anos e desvio padrão de 6,98. A mediana das idades foi de 30 anos. No que se refere à procedência, $34(68,0 \%)$ eram da cidade do Recife, estado de Pernambuco (PE); cinco $(10,0 \%)$ do município de Jaboatão dos Guararapes (PE); três $(6,0 \%)$ de Olinda (PE) e oito casos $(16,0 \%)$ procediam de outras cidades: Sairé (PE); Carpina (PE); Surubim (PE); Garanhuns (PE); Paulista (PE); Săo Joaquim do Monte (PE); Manaus (AM) e Curitiba (PR). Quanto ao fator de risco dos pacientes, $26(52,0 \%)$ eram homossexuais masculinos; dez $(20,0 \%)$ heterossexuais; seis bissexuais $(12,0 \%)$; seis $(12,0 \%)$ heterossexuais usuários de drogas endovenosas e dois $(4,0 \%)$ homossexuais masculinos usuários de drogas endovenosas.

Exame do LCR - O exame do LCR foi realizado em todos os pacientes à admissăo, independentemente de apresentarem ou não sinais clínicos de comprometimento neurológico. A análise do LCR incluiu: pressão; citologia (número de células e aspectos citomorfológicos); proteina total e eletroforese das proteínas; glicose e cloretos. Foram realizados testes imunológicos para toxoplasmose (reação de imunofluorescência indireta), sífilis (reação de floculação do VDRL e reação de fixação do comlemento de Wasserman) e infeç̧ðes virais : citomegalovinus (CMV), Varicella-zoster (HZV), Herpes simplex (HS) e HIV1 (reaçăo de fixação do complemento

Tabela I. Alteraçōes gerais do LCR observadas nos 45 pacientes com AIDS internados no Serviço de Doenças Infecciosas e Parasitárias/HC/UFPE. Recife-1991/93.

\begin{tabular}{lcc}
\hline LCR* & Frequência Absoluta & $\%$ \\
\hline Aumento da pressão & 13 & 28,9 \\
Hipercitose & 22 & 48,9 \\
Hiperproteinorraquia & 23 & 51,1 \\
Hipergamaglobulinorraquia & 25 & 55,5 \\
Hipoglicorraquia & 6 & 13,3 \\
Hipoclororraquia & 18 & 40,0 \\
Anticorpo HIV reagente(ELISA) & 42 & 93,3
\end{tabular}

(*)Valores de referência (normais): pressão 10 a 20 mmH2O (deitado, manômetro de Claude); células 0 a 4; proteina total normal 10 a $25 \mathrm{mg} \%$ (sub occipital) e 15 a $42 \mathrm{mg} \%$ (lombar); gamaglobulina 7 a 14\%; glicose 40 a $70 \mathrm{mg} \%$; cloretos 700 a $750 \mathrm{mg} \%$. 
Tabela 2. Etiologia das infeç̧öes detectadas através do LCR nos pacientes com AIDS internados no Serviço de Doenças Infecciosas e Parasilárias/HC/UFPE. Recife-1991/93.

\begin{tabular}{lcc}
\hline Infecção & Frequência absoluta & $\%$ \\
\hline Toxoplasmose & 18 & 42,8 \\
Criptococose & 4 & 9,5 \\
Tuberculose & 4 & 9,5 \\
Sifilis & 2 & 4,8 \\
Citomegalovirose & 2 & 4,8 \\
Candidiase & 2 & 4,8 \\
Infecçóes associadas* & 10 & 23,8 \\
Total & 42 & 100 \\
\hline
\end{tabular}

(*) ver Tabela 3 .

Tabela 3. Infecções associadas detectadas através do LCR nos pacientes com AIDS internados no Serviço de Doenças Infecciosas e Parasitárias/HC/UFPE. Recife-1991/93.

\begin{tabular}{lcc}
\hline Infecçðes Associadas & Frequência absoluta & $\%$ \\
\hline toxoplasmose + criptococose & 2 & 20,0 \\
toxoplasmose + Herpes simplex & 2 & 20,0 \\
toxoplasmose + candidiase & 1 & 10,0 \\
toxoplasmose + sifilis & 1 & 10,0 \\
toxoplasmose + CMV + Herpes simplex & 1 & 10,0 \\
toxoplasmose + CMV & 1 & 10,0 \\
sifilis + tuberculose & 1 & 10,0 \\
sifilis + Herpes simplex & 1 & 10,0 \\
Total & 10 & 100 \\
\hline
\end{tabular}

CMV, citomegalovirus.

Tabela 4. Diagnóstico final dos pacientes* com AIDS internados no Serviço de Doenças Infecciosas $e$ Parasitárias/HC/UFPE que apresentaram LCR normal. Recife-1991/93.

\begin{tabular}{lcc}
\hline Diagnóstico & Frerquéncia absoluta & $\%$ \\
\hline Dermatite seborréica + Herpes zoster (torácico) & 1 & 25,0 \\
Dermatite seborréica + Furunculose & 1 & 25,0 \\
Candidiase gastrointestinal & 1 & 25,0 \\
Sarcoma de Kaposi + Infecção respiratória & 1 & 25,0 \\
Total & 4 & 100
\end{tabular}

(*) Pacientes que não apresentaram queixas clinicas sugestivas de comprometimento neurológico; este também não foi detectado por outros meios diagnósticos(TC crânio- encefálica e exame neurológico). 
para Herpes virus/CMV e anti-HIV ELISA). Investigação bacteriológica e micológica ( exame direto c cultura ), assim como reação de látex para criptococose, e, para bacilo de Koch, testes de Levinson e da adenosino deaminase (ADA) foram também realizados. Todos as amostras de LCR foram analisadas no mesmo laboratório seguindo sempre a mesma metodologia.

\section{RESULTADOS}

O LCR esteve alterado em 45 doentes $(90,0 \%)$. As principais alterações encontradas foram hipergamaglobulorraquia, 25 casos $(55,5 \%)$; hiperproteinorraquia, 23 casos $(51,1 \%)$ e hipercitose, 22 (48,9\%). Anticorpo anti-HIV (Elisa) reagente foi observado em 42 pacientes $(93,3 \%)$. (Tabela 1 ).

Quanto a etiologia das infecçōes detectadas através do LCR nos pacientes estudados, toxoplasmose isolada ou associada a outros agentes foi a mais frequentemente encontrada, 26 pacientes $(57,7 \%)$ (Tabela 2 e 3 ). O LCR esteve normal em quatro casos $(8,0 \%)$, sem queixas sugestivas e/ou alteraçס̃es do sistema nervoso. Estes, não apresentavam comprometimento neurológico detectado por outros meios diagnósticos (tomografia computadorizada crânio-encefálica e exame neurológico) (Tabela 4).

Um paciente apresentou LCR normal, mas tinha comprometimento neurológico revelado pelo estudo tomográfico crânio-encefálico.

Não foram registradas complicações pós-punção para colheita de LCR.

\section{DISCUSSÃO}

A AIDS vem sendo um grande problema em todo o mundo ${ }^{6}$. A prevalência do comprometimento neurológico em pacientes com AIDS tem variado de 10 a $70 \%{ }^{7}$ Estima-se que pelo menos em $10 \%$ dos casos, a sintomatologia neurológica é a manifestação inicial ${ }^{2}$.

A alterações do LCR (número de células, proteina total, gamaglobulina e aumento de imunoglobulina $\mathrm{G}$ ) podem ser observadas em qualquer época da doença, o que é explicado pela presença do vírus no LCR e/ou SNC ${ }^{3-5.8 .9}$ Anti-HIV no LCR é encontrado em até $88 \%$ dos casos de AIDS $^{4}$. Nos pacientes estudados, a pesquisa de anticorpo anti-HIV (ELISA) foi reagente em 42 casos $(93,3 \%)$, dado este que confirma o que já foi descrito na literatura ${ }^{1,7}$.

Associação de patologias pode ocorrer em cerca de $66 \%$ dos casos ${ }^{4}$. Mas, na presente casuística, ela só ocorreu em dez pacientes $(23,8 \%)$. Entre as infeç̧ðes oportunistas, a toxoplasmose, isolada ou associada, foi sem dúvida a mais frequente, sendo detectada em 26 casos $(57,7 \%)$, seguida de criptococose em $6(13,3 \%)$; tuberculose em $5(11,1 \%)$ e sifilis em $5(11,1 \%)$.

No presente estudo o LCR esteve alterado em 45 casos $(90,0 \%)$. Apenas 4 pacientes(8\%) tinham LCR normal e não apresentavam comprometimento neurológico. Estes achados permitem sugerir que o exame de LCR deva ser realizado em todos os pacientes com AIDS, em qualquer fase da doença, devendo ser o mais completo possivel.

Quadros de tipo inflamatório foram os que predominaram. De fato, as alteraçðes do perfil citomorfológico, na vigência de hipercitose, foram os achados mais comuns. A expressividade dessas alterações nem sempre se apresentaram segundo os parâmetros clássicos. Além do que, o próprio HIV poderia ser o responsável pela reação inflamatória observada, atuando isoladamente ou em associaçăo a outros patógenos, demonstrando a complexidade da doença e do seu diagnóstico.

As alteraçðes do LCR permitem, portanto, diagnosticar complicações tratáveis sobrepostas à patologia de base (AIDS), contribuindo assim para a melhoria da qualidade de vida e sobrevida desses doentes.

O LCR em mãos experientes é, sem dúvida, de grande ajuda na elucidação clínica do comprometimento neurológico nos pacientes com AIDS, independentemente da fase de doença em que se encontrem, mas especialmente nos grupos IV da classificação do CDC. 
Agradecimentos - Ao Professor José Antonio Livramento (Livre Docente do Departamento de Neurologia do Hospital das Clínicas da Faculdade de Medicina da Universidade de São Paulo), pela orientação e pela correção do manuscrito.

\section{REFERÊNCIAS}

1. Gabuzda DH, Hirsch MS. Neurological manifestations of infection with human immunodeficiency virus. Ann Intern Med 1987;107:383-391.

2. Goldstick L, Boder R. Spinal cord degeneration in AIDS. Neurology 1985;35:108.

3. Livramento JA, Machado LR, Spina-França A. Sinalização do líquido cefalorraquidiano em doenças inflamatórias crônicas do SNC. Arq. Neuropsiquiatr 1986;44:351-358.

4. Livramento JA, Machado LR, Gomes HR, Vianna LS, Spina-França A. AIDS a CSF laboratory experience on 470 cases in a 7 years time period. Arq. Neuropsiquiatr 1992;50:56-59.

5. Livramento JA, Machado LR, Spina-França A. Anormalidades do liquido cefalorraqueano em 170 casos de AIDS. Arq. Neuropsiquiatr 1989;47:329-331.

6. Puccioni-Sohhler M, Correa RD, Perez MA, Schechter RC Filho, Novis SAP. Complicaçðes neurológicas na sindrome da imunodeficiência adquirida: experiência do HUCFF-UFRJ. Arq. Neuropsiquiatr 1991;49:159-163.

7. Schechter M. Manifestaçðes neuropsiquiátricas na sindrome da imunodeficiência adquirida(SIDA/AIDS). In: Schechter M, Marangoni DV. - Doenças infecciosas: conduta diagnóstica e terapêutica. Rio de Janeiro: Guanabara Koogan, 1994: 442-448.

8. Spina-França A, Livramento JA, Machado LR, Bacheschi LA, Nóbrega JPS. Líquido cefalorraqueano na sindrome da imunodeficiência adquirida: análise de 50 casos. Arq. Neuropsiquiatr 1987;45:412-417.

9. Vianna LS, Gomes HR, Castro LHM, Machado LR, Livramento JA, Spina-França A. Líquido cefalorraqueano na AIDS: análise de 291 casos. Arq. Neuropsiquiatr 1990;48(Suppl): S413. 